\title{
Erratum to: Chemotherapy-Related Cognitive Dysfunction
}

\author{
Jeffrey S. Wefel • Sanne B. Schagen
}

Published online: 26 April 2012

(C) Springer Science+Business Media, LLC 2012

\section{Erratum to: Curr Neurol Neurosci Rep \\ DOI 10.1007/s11910-012-0264-9}

\section{Wefel JS, Schagen SB: Chemotherapy-Related Cognitive}

Dysfunction. Curr Neurol Neurosci Rep 2012.

The abovementioned article was published online first for the June 2012 issue of Current Neurology and Neuroscience Reports (volume 12, issue 3).

The study by Deprez et al. from 2011 (1) is missing in the listing of the 23 cross-sectional neuropsychological studies.
Reference 60 mistakenly cites the cross-sectional study by Deprez et al. instead of the prospective study by this group (2).

\section{References}

1. Deprez S, Amant F, Yigit R, et al. Chemotherapy-induced structural changes in cerebral white matter and its correlation with impaired cognitive functioning in breast cancer patients. Hum Brain Mapp. 2011;32:480-93.

2. Deprez S, Amant F, Smeets A, et al. Longitudinal assessment of chemotherapy-induced structural changes in cerebral white matter and its correlation with impaired cognitive functioning. J Clin Oncol. 2012;20(30):274-81.

The online version of the original article can be found at http://dx.doi. org/10.1007/s11910-012-0264-9.

J. S. Wefel $(\bowtie)$

Department of Neuro-Oncology, MD Anderson Cancer Center,

1515 Holcombe Boulevard, Unit 431,

Houston, TX 77030, USA

e-mail: jwefel@mdanderson.org

\section{S. B. Schagen}

Department of Psychosocial Research and Epidemiology,

Netherlands Cancer Institute-Antoni van Leeuwenhoek Hospital,

Plesmanlaan 121,

1066 CX Amsterdam, The Netherlands

e-mail: s.schagen@nki.nl 